\title{
Placemaking with teenagers. Experiences driven from thematic workshops on urban planning.
}

\author{
Inês Almeida [0000-0003-4030-495X], Universidade Lusófona, Interdisciplinary \\ Research Centre for Education and Development, Lisbon, Portugal. ines.almeida@ulusofona.pt \\ Joana Solipa Batista [0000-0002-2089-8722], Universidade Lusófona, Interdisciplinary \\ Research Centre for Education and Development, Lisbon, Portugal. joana.batista@ulusofona.pt \\ Filipa Lourenço [0000-000 I-7390-0892], Universidade Lusófona, Interdisciplinary \\ Research Centre for Education and Development, Lisbon, Portugal. filipa.lourenco@ulusofona.pt
}

\begin{abstract}
This chapter discusses topics of interest produced in the context of a pilot phase of thematic workshops on urban planning with teenagers in the Alvalade neighbourhood (Lisbon). The workshops were developed to encompass topics of interest relating to teenagers' perceptions, representations and uses of space. Another focus was on perceptions and uses of Information and Communication Technology (ICT). Finally, the workshops tackled the opportunities for participation and civic engagement and teenagers' contribution in the design and planning of public open spaces. On the one hand, this contribution reflects on how to engage teenagers in critically thinking about the city-making process. Along this line, it reflects on teenagers' participation and placemaking and compares initial expectations of researchers with the emerging topics of interest arising within the workshops. But also, on the other hand, it ponders on how to promote in these students a more active civic participation. It is suggested that education for citizenship can be indirectly addressed and explored through the activities conducted within the urban planning workshops. And, through this, another goal can be achieved: empowering teenagers with tools and knowledge to become more active and engaged citizens. Even though this was not initially planned, and therefore no formal evaluation of such results was conducted, it leaves room for reflection in the present and for future work.
\end{abstract}

Keywords - Public Open Spaces; teenagers; citizenship education; ICT; placemaking 


\section{INTRODUCTION}

The role of citizens in the process of transforming and building their environment has been widely discussed and put to practice through several strategies and mechanisms: either formal or non-formal; promoted by the state or by citizen movements, on a city scale or neighbourhood level (Wilhelmer, 2016; Holmes, 201 I). Placemaking encompasses several concepts which operationalise such notions. Placemaking ideas came to be through the work of Jane Jacobs and William $\mathrm{H}$. Whyte, who highlighted the relevance of active neighbourhoods and attractive public spaces for social and cultural well-being (PPS, 2018). Overall, placemaking seeks to promote the creation of attractive places that people will more likely care about and relate to, where they would want to be and feel safe in, and where different facilities and experiences can be offered.

However, not all citizens are given the same possibilities and opportunities to participate and manifest their expectations for the places where they reside, for example, due to socioeconomic, educational or age status (van Holm, 2019; Armingeon \& Schädel, 20I5; Stephens, 20I2; Valentine, 2004). Hereinafter, this chapter will have a twofold focus. First, on teenagers who are, due to their age, excluded from this process of participation. Second, on the strategies available to counteract this reality and engage them in the process of city-making, enabling them to be active citizens. Placemaking can be one of such approaches, building bridges between professionals and several other stakeholders.

As is the case with other age groups, teenagers have unique and specific interests regarding space in a city. Despite this well-known fact, their needs and wishes are not always accounted for by those who plan and design cities and their public spaces, being often withdrawn from engaging in the process and denied the right to exercise their citizenship. Adults decide on their behalf assuming they are acting in their best interest. This is caused either by an advocacy that teenagers should not be deprived of a life free of worries, or by an assumption that they are not sufficiently equipped to make decisions on their own (White, 200 I; Laughlin and Johnson, 20I I; Valentine, 2004). As part of the activities undertaken within a European research project, a series of thematic workshops on urban planning were conducted in Lisbon. The activities were designed and implemented to test possibilities to engage teenagers in placemaking, and explore teenagers' representations and needs regarding public open spaces. The pilot phase engaged forty-nine 10th grade students, aged between 15 and 19 in a secondary school in Alvalade (Lisbon) during the 2017-18academic year. The workshops totalled 24 hours of contact divided by 90 minutes sessions. The workshops and their objectives were planned, but the activities were designed as the sessions were taking place, providing students with the opportunity to contribute with ideas and adjust the activities to their emerging requests. This chapter confronts results from the pilot phase of the workshops with researchers' initial 
expectations, discusses topics of interest emerging from the activities, and reflects on teenagers' participation and placemaking approach.

\section{PUBLIC SPACES UNDER THE EYE OF TEENAGERS: IN LINE WITH CITIZENSHIP EDUCATION}

Public space is a privileged gathering place for individuals, a place where citizenship can (and should) be exercised. The responsibility for the creation and conception of these public places falls upon institutions of power. And upon citizens falls the awareness of their role in society to be participants in the enhancement of what belongs to the community. Analysing the concept of public space is understanding its structure in the evolution of contemporary society. Reflecting on public space implies thinking space as a resource, a product, a social, political and symbolic practice, a place which serves citizens, and where they can gather to express a public opinion. In other words, this involves considering public space as part of the sphere of public power (Habermas, 1984). When we talk about citizens, we cannot dismiss their right to exercise their citizenship and manifest their opinions and needs publicly. However, some groups, such as teenagers, tend to be disregarded and their needs neglected. And indeed, during the process of city planning and design, teenagers' opinions are frequently not heard. Justifications for this are adults' perception of teenagers as lacking the necessary attributes, e.g. responsibility, motivation, competences, interest, legitimacy or power, to participate (Laughlin \& Johnson, 20I I; Passon, Levi, and del Rio, 2008). Nevertheless, teenagers, as users of public spaces and as citizens, have a voice that must be heard and needs that must be satisfied. Hence, citizenship education, as an empowering tool to engage political and civil society, both at individual and group level (Schugurensky \& Myers, 2003), should be a goal of all governments with a view to bringing up active and transformative citizens (Banks, 2008). This will reflect the pertinence of space as a product at the service of its users (Lefebvre, 1973). It is commonly accepted that national governments have been given several forms and levels of education as a way of fostering knowledge, skills and virtues necessary for youth to become "good citizens". However, it is known that most citizenship education was developed to be an instrument to keep and reproduce economic, social and political structures of society (Giroux, 1980).

The city is understood as a public space project, a product intended for the use of those who will appropriate it. Teenagers, as users, must be in line with the processes of knowledge production and planning of public space. That would only be a reality if they are granted the opportunity to participate and contribute, and the recognition that they possess the necessary creativity and capacity to transform and shape their communities and societies.

In the dimensions that Borja sets forth for public space on the social and cultural scale, the interdependence of this trilogy: city - public space - citizenship, it is argued 
that "(...) our life depends to a large extent on this relation (...)" (Borja, 2003: 22). The underlying thesis is that none of these concepts can exist independently. In this sense, individual rights per se do not necessarily entail a participation in the formation of the city; therefore, a fully-exercised citizenship is needed for collective and active city shaping, as well as for the construction of significant places for its citizens.

It is so much in this sense that public space is presented as the prime space to facilitate dialogue, experiences and social cohesion. Public space gives way to the objects and sets them in the territory, drawing to itself different users. In it lies the gathering point, which unveils those who come to it and stay there if an empathy with space is developed (Lourenço, 2019). The importance of citizenship education as an instrument to empower teenagers should be not only conceived as a set of rhetoric rights, but understood as a way of living, for the individuals and for the social well-being. This kind of capacity may prove difficult to implement due to the lack of knowledge of concepts but that does not mean a lack of ideas. Concepts can be learned; a lack of ideas denotes an absence of freethinking and a fragile grasp on citizenship. The ability to co-create new "empathetic" spaces accordingly to the needs and wishes of teenagers should begin with giving them space to interact with local authorities - a way of getting out of rhetoric lines into a participative line.

Following the above-mentioned theoretical assumptions, a series of thematic workshops on urban planning was designed. The purpose was to operationalize and implement such premises so as to bring some insights into the research project in which they are integrated - whose goal is to develop strategies (co-creation) and tools (ICT) to increase the quality of public open spaces and social cohesion effects. The sessions, goals and results of the workshops will be presented in the next section.

\section{THEMATIC WORKSHOPS WITH TEENAGERS}

A series of thematic workshops on urban planning was developed in Lisbon aiming at designing recommendations for more attractive, responsive and inclusive public open spaces. The target group was constituted by teenagers and the area of study was the Alvalade neighbourhood. This neighbourhood is located in the north of Lisbon and is a well-known example of a planned and structured neighbourhood, established by The Urban Development Plan of Alvalade (1930-45), designed by João Guilherme Faria da Costa. In this neighbourhood many public spaces can be found, both open and closed, with different functions and uses. The residential areas are mixed with retail zones as well as services and equipment for daily use (Costa, 2002). A neighbourhood school was involved, as partner, to facilitate access to teenagers. The fact that the school was participating in a pilot project led by the Ministry of Education that allowed it to decide the curricular content for a certain number of hours also facilitated logistics. Two $10^{\text {th }}$ grade classes ( $N=49$, aged I 5 to 19) were engaged, chosen for participation by the school administrator. 


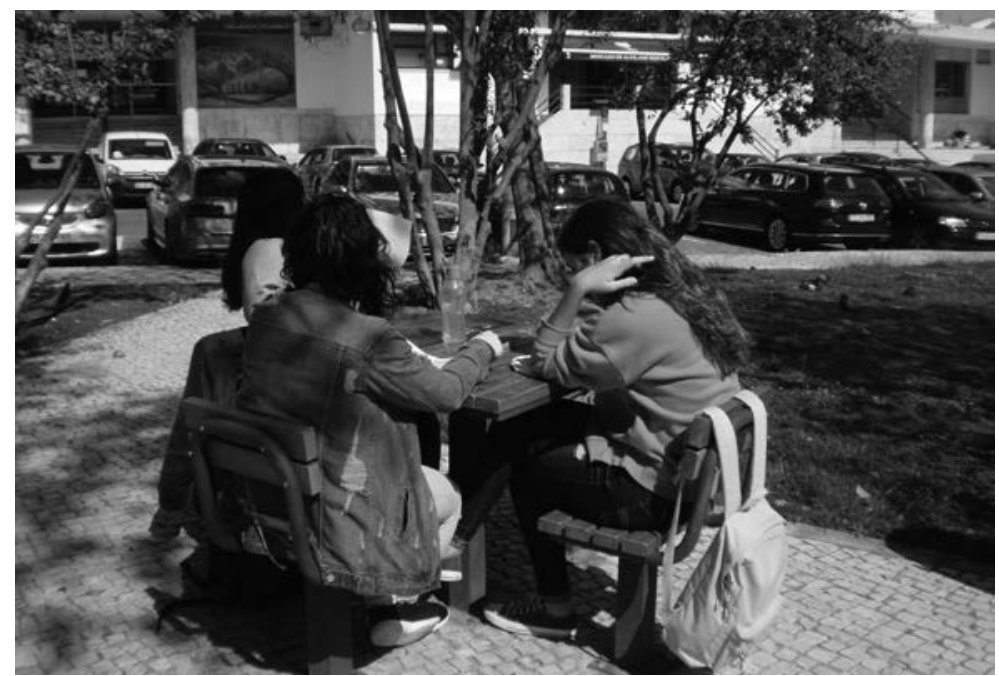

Fig. I. Outdoor activities - observation of public open spaces in the Alvalade neighbourhood. Photos: C3Places Archive.

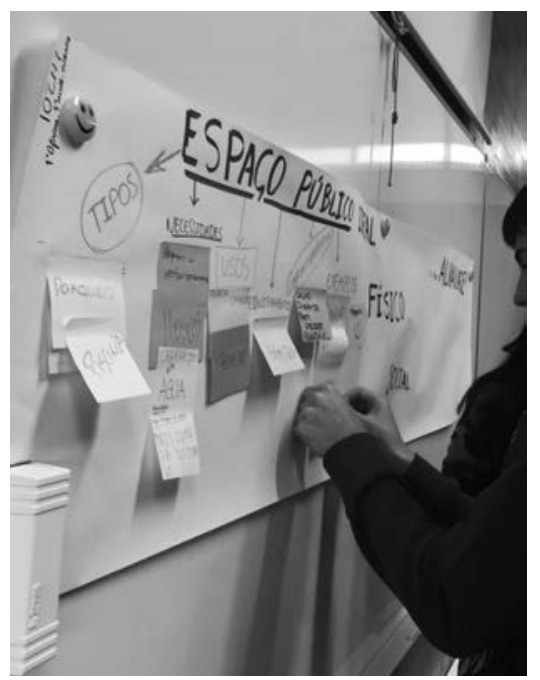

Fig. 2. Interactive class discussion of public spaces.

Conceived to engage students in different achievements, the thematic workshops had four major purposes. Firstly, they intended to raise interest in urban space through the discussion of opportunities and problems present in public open spaces, and to debate ideas on the uses of Information and Communication Technologies (ICTs) to increase public open space use. Secondly, they were expected to encourage outdoor activities. This was accomplished by sessions in outdoor spaces in the Alvalade neighbourhood, as structured observations of public open space (Fig. I). Other activities were designed for the classroom, such as interactive discussions, with sticky notes, where teenagers explored their ideas on the ideal public space (Fig. 2). Such activities aimed at exploring and discussing teenagers' knowledge of 
public open spaces and the role of public space in improving environmental quality and increasing citizens' quality of life. Thirdly, with the students' input, the thematic workshops aimed to develop arguments to question whether public open spaces answer their needs or not, incorporating the role of ICTs for future public spaces. Finally, it was expected to introduce the scientific research process, discussing and presenting research methodologies and the applicability of research findings to citizens' daily life. In the meantime, a preliminary report was published which provided reflections on the process of development and implementation (Almeida et al., 2018).

In this way, four themes were tailored to operationalise the above-mentioned goals, and each paralleled a thematic workshop composed of four sessions. Thus, for each theme specific activities were developed to engage teenagers:

Thematic workshop I - "A critical look at the city" aimed at presenting, conceptually and practically, cities, urban planning, urban morphology and the role of public open spaces. Activities consisted of: I) a theoretical introduction and presentation of the project, workshops and expectations; 2 ) an expedition through the Alvalade neighbourhood to observe and describe the space; 3 ) a semi-structured interview conducted by teenagers to their colleagues to explore their perceptions of their neighbourhoods and introduce the scientific research process; 4) and, finally, a discussion of concepts, perceptions, uses, and problems in public spaces. Researchers also passed on a brief questionnaire to assess students' demographic profile, use of ICTs and use of public space.

Thematic workshop 2 - "Construction of the city" was conceived to address the planning and building of cities, their social and environmental role, opportunities to participate in the planning process, and discussing tools and projects addressing these topics. The activities entailed two sessions with professionals. The first session, held with representatives from the Alvalade Parish Council (Public Space Division)', introduced public policies, strategies and demands in constructing or transforming public space in Alvalade, in general and in regard to teenagers' needs. In the second session, tools and opportunities to participate in placemaking were discussed. This session was attended by the Parish Council representatives, members of a civic movement $t^{2}$ and by a representative of a digital crowdfunding platform ${ }^{3}$. Another activity involved discussing values, ideas and identified problems in the communal urban resources. Finally, a discussion of different transformation proposals took place, and a consensus had to be achieved considering the different needs and interests of multiple actors and on the participation opportunities, tools and processes discussed in the previous sessions.

\footnotetext{
' https://www.jf-alvalade.pt/

${ }^{2}$ The movement Caracol da Penha developed a proposal to transform a derelict space into a public place. This proposal won Lisbon's Participatory Budgeting in 2016. https://www.caracoldapenha.info.

${ }^{3}$ PPL platform. https://ppl.pt
} 
Thematic workshop 3 - "The digital era and the city" sought to address ICTs and lifestyles, exploring how the digital generation perceives itself and the role of ICTs in the production of cities. A presentation of different inputs and information on technological advances and transformations brought (or not) to the city was provided. The screening of a documentary on different dimensions of and perspectives on technology was another activity. Outdoors, teenagers observed (with the assistance of a recording grid) the presence of ICTs in public open spaces in Alvalade and the uses of public open spaces. In the last session students organized and mediated a debate on the advantages and disadvantages of digital technology.

Thematic workshop 4 - "Project and design of an urban public open space" sought to discuss the planning and construction of public open spaces, considering technical, social and environmental aspects. It aimed at debating the history and role of public open spaces in the city and examining the needs, expectations and preferences of different users. It also involved recognising the interactions between users and possible conflicts that may arise while competing for available space. Activities in this final workshop were more directed at understanding how space is designed and projected, with exercises to explore spatial representation (orientation, scale, shapes, designs and descriptive documents) required in the design of proposals. An activity to practice the design of proposals for the school yard (well-known space that they could see from the classroom) was assigned to students. Finally, they were asked to translate their needs, ideas and preferences regarding public open spaces into a proposal for the transformation of a public open space in the Alvalade neighbourhood.

As mentioned above, these goals were operationalised as the sessions were being implemented, to allow students' needs and ideas to be addressed, as well as to better deal with the external factors (such as the weather) that constrained some of the sessions. The next section will confront the initially established goals for the workshops with some preliminary results drawn from the analysis conducted so far.

\section{TEENAGERS' RESPONSE TO THEMATIC WORISHOPS: EXPECTATIONS VS RESULTS}

The workshops produced varied materials. A methodological decision was made by the researchers on which data should be analysed in more depth. Such materials as questionnaires and the facilitators' observational notes, as direct tools for data collection, were prioritized. Questionnaires had closed questions, which were analysed quantitively, and open questions, subject to thematic analysis (Braun \& Clarke, 2006). Other data resulting from materials that provided support for the activities and exercises complemented and reinforced these analyses. Materials were compiled, organized thematically and qualitatively analysed by researchers. It is important to clarify that most of the analysed materials (except for the questionnaires) emerged from the workshops' interactions. In other words, in many of these materials the data, ideas, needs or proposals that were collected emerged from collective 
reflections and discussions. In varying degrees, depending on the material, the workshop facilitators and the teachers that accompanied the class also intervened.

While discussing and testing interactive activities to engage teenagers in placemaking we need to acknowledge that the process is always a contextual one. External factors influence activities, adding a feature of unpredictability that may hinder the design of generalised recommendations. In the development and implementation of these urban planning thematic workshops, some external factors, such as weather conditions and school organizational and administrative processes ${ }^{4}$, influenced (either for better or for worse) the outcome of the sessions or of specific activities (Almeida et al., 2018). However, that is not necessarily negative. providing instead opportunities for more flexible processes of placemaking (and we can wonder if also of research). Adaptability to the needs and preferences of the engaged audiences is paramount, as it translates into a final product that is also flexible, with a higher capacity to adapt to users' needs and to attract people.

The results from the four thematic workshops, in general, pointed to an adequacy of the process and the achievement of the pre-established goals. Due to the cumulative feature of the workshops and the articulation of themes and activities, the reflection on expectations and outcomes was done transversally. Data of interest to reflect on each of the themes and on teenagers' perceptions were present across sessions, regardless of which workshop focused on a specific theme. The main> reflections of interest emerging from the thematic workshops can be organized in the following topics:

Perceptions on space and use of space: Regarding teenagers' knowledge of city concepts and city morphology, it was manifest, throughout the sessions, a lack of information on such notions and concepts. It was not possible to ascertain why teenagers had such a poor grasp of these concepts, but a possible explanation is their absence from the formal curricula. From the first session, concepts of urban planning were introduced to be later used in several activities. During the subsequent activities it was noticeable that these concepts were appropriated and correctly applied.

In the first session, teenagers were asked to complete a questionnaire to draw their demographic profile, use of ICTs, use of public open spaces (quantitative - closed questions) and their perceptions on space (qualitative - open questions). Their perceptions on space were assessed by open questions: known spaces near their home and in Alvalade ${ }^{5}$; what was understood by concepts of city, public space, urban

\footnotetext{
${ }^{4}$ For example, the mandatory presence of a teacher during the sessions meant that when the assigned professor was absent the session could not occur.

${ }^{5}$ As later revealed by the profile information of the students enrolled in the workshops, only $15 \%$ are residents in the Alvalade neighbourhood, the majority live in other Lisbon neighbourhoods and even in other municipalities. While developing and operationalising the sessions, the data from students' registration in the Alvalade School Group already revealed this situation. For this reason in the questionnaire the differentiation was made between spaces in Alvalade and near home. The goal was to capture a better image of the use of public space and to compare possible differences between public space use near the home and near the school.
} 
planning, public space maintenance; perception of personal contribution to planning; and short description of their neighbourhood. Qualitative data from questionnaires was also explored in Smaniotto Costa et al. (2018), in a discussion of young people's broader representations of the relation between people - public places - and ICTs. A second questionnaire was also developed, aimed at providing a base for students to question each other on how they saw their neighbourhood (what they liked/ didn't like, problems and solutions, better and worse places in the neighbourhood, use of public open spaces and activities, and general evaluation of the neighbourhood). Answers were written down by students and transcribed for analysis. From the last section of the first questionnaire (QI), from the second questionnaire (Q2), and from an analysis of the final discussion from thematic workshop it was possible to ascertain that teenagers' perceptions on space could be divided into two dimensions. A first dimension referred to conceptual perceptions. Although simplistic, incomplete and, in some cases, revealing misconceptions, teenagers' conceptual perceptions encompassed many of the different levels (demographic, social, and subjective features/physical, material, and administrative features) at play in the theoretical discussion of the urban fabric and public spaces. And a second dimension addressed perceptions on space put in terms of experience of space (either direct, through use, or indirect, through proximity).

Another topic of interest is related to the perception of the neighbourhood. Most of the students had a positive opinion/experience of their neighbourhood even when the perception of others is negative ("I like my home, even if [located] in a known confrontational neighbourhood, because there's a lot of turmoil there" (QI - Respondent 13). Neighbourhood is also seen as positive even when negative features are identified ("In my opinion there is nothing interesting about my neighbourhood. Nevertheless, I like living there, since it is a quiet and tranquil neighbourhood" (Q I - Respondent 36). The latter quote also reveals a common trait identified in Q I and Q2, associating a positive experience of the neighbourhood with features of calmness, tranquillity and peaceful environment. Other characteristics that making their neighbourhood a good place to live were the existence of services and infrastructures, and the residents and their interactions. Those who have a negative opinion/experience of their neighbourhood justified it as a consequence of specific features such as location/difficult accessibility, feeling of social exclusion, insecurity and unattractiveness. Matters of accessibility and public transportation were recurrently pointed out by teenagers as important.

The role of public open space was introduced, and its social and environmental benefits discussed. From class interactions, the use of public space by teenagers appears to be low; however, this contradicts findings from QI (section on use of public space) $-81 \%$ use them frequently (sometimes during the week $-65 \%$; many times, during the week - 10\%; and daily - 6\%). Still, there is a need to balance reported use of public space against observed difficulties in understanding what 
qualifies as public space (a topic to be developed in the following section). Different types of public open spaces where identified by teenagers, namely, parks, gardens, squares and streets. A comprehensive list of known public open spaces, either near their homes or in Alvalade, was compiled. Almost all students identify a park or green area near the place they inhabit and point out different purposes for using it, such as physical activity, being with friends or family, walking the dog, playing and doing sports. In Q2, when asked to identify the best places in their neighbourhoods, the majority (15) identified public spaces, mostly gardens and parks.

Despite teenagers' positive reflection on the urban fabric, until the end of the sessions teenagers' difficulty in differentiating public open spaces and public closed spaces and/or privately-owned public spaces persisted. In QI, when questioned about what spaces they use, the most frequent answers point to commercial spaces such as shopping centres, coffee houses and restaurants and markets/supermarkets (near the home, 33\% of answers and in Alvalade, 25\%). Overall, they consider public closed spaces such as shopping malls to be open spaces, highlighting the possibility to access it: if it is open to the public and its entry is free of charge, teenagers perceive the space as open and public. Teenagers also reveal they do not feel unwelcomed or excluded from this type of spaces, neither perceive limitations in their use.

Participation: Prior to the thematic workshop on participation, teenagers were questioned about what they perceived to be their contribution to planning $(\mathrm{QI})$. Most answers indicate either a passive contribution, like maintaining existing conditions of the spaces they use, or a more active contribution but in very specific instances, for instance, recycling, identifying problems and keeping the spaces clean. Thirty seven percent (37\%) didn't reply when asked how they could contribute, which may reveal a lack of understanding by teenagers of what would be expected of them if they were allowed to participate in urban planning. This was also observed during class interactions, especially when discussing proposals for public open spaces. In the second thematic workshop, teenagers were confronted with several means available for civic participation, listening directly to contributions from public authorities, grassroots movements and private/market initiatives (Fig. 3).

Taking the first - the state - teenagers were almost automatically excluded, since the most common strategy involves participatory budgets. The presentation of proposals used to be available only to people over 18 years old, but it was mentioned by the authorities that it will became available to all aged 16 and older. However, this still echoed little with this group of teenagers. Representatives discussed other strategies that could be used to communicate with local authorities and propose specific solutions or ideas, but not specially designed for youngsters. Nevertheless, teenagers seem to manifest a generalized lack of interest in taking part in any civic action. Mostly, they are fully aware of the temporal gap between 


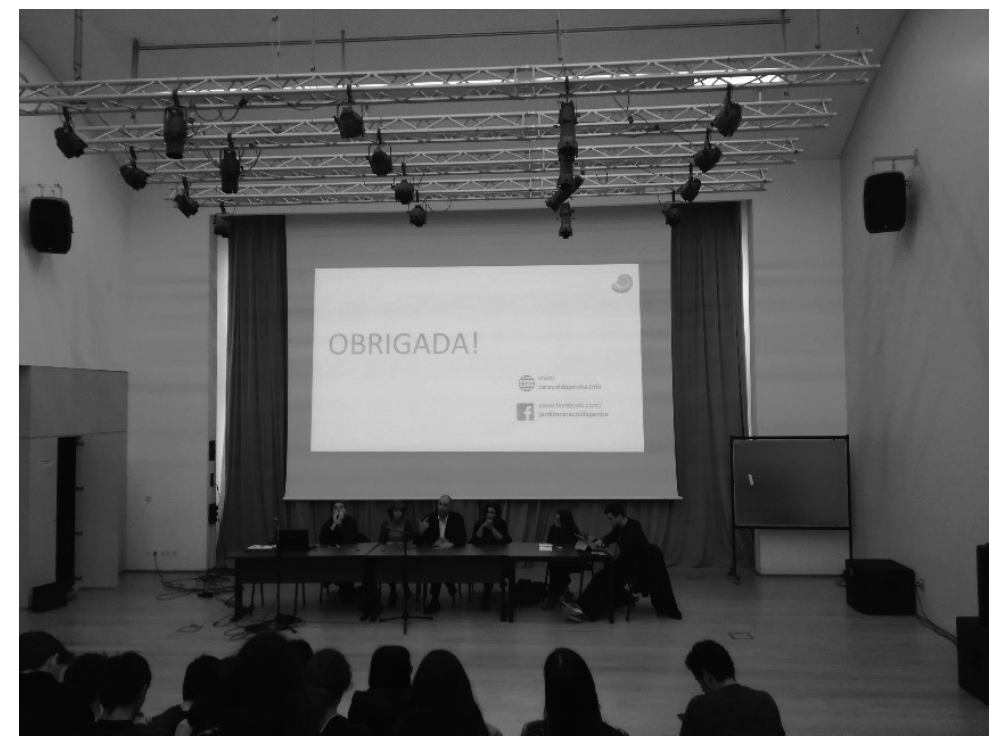

Fig. 3. Session with representatives from local authorities, grassroots movement and private/market initiative.

discussing, deciding and implementing any ideas. Teenagers are mindful that they will hardly ever benefit from any result arising from such a participatory process. It was not possible to fully explore the conditions and opportunities for teenagers' voluntary participation and engagement in placemaking because the thematic workshops were developed under a context of formal education, and this influenced the process. It was convenient, by providing access to a public that is difficult to engage in after school activities and ensuring their regular presence. On the other hand, though, in school activities (as was the case) participation was mandatory, which compromised a neutral assessment of teenagers' motivation.

Use and advantages and disadvantages of technology: The pervasiveness and ubiquity of ICTs were discussed with students, e. g. in exercises to stimulate teenagers to reflect on ICTs and discuss ideas with peers (Fig. 4).The materials analysed from thematic workshop 3 and from the questionnaire section on the use of ICT allowed us to explore teenagers' perceptions and uses of ICT. Teenagers recognize its impact on their lives, particularly on the social dynamics, and can recognize and coherently discuss the dangers and benefits associated with ICT, for citizens, families, communities and cities. They recognise the importance of ICT in the city, expressing the possibilities to create a more connected, efficient and sustainable city. But, on the other hand, their discourse reveals a heightened concern with the consequence of the excessive use of ICT on the quality of interpersonal relationships and on psychological well-being. Also, teenagers didn't recognize the presence of ICT in public open spaces as paramount to increase their use of a place. The only reference was made to the need for wi-fi signal, so they can use their 
mobiles in public spaces to conduct the most frequent activities: navigate social media and chat online.

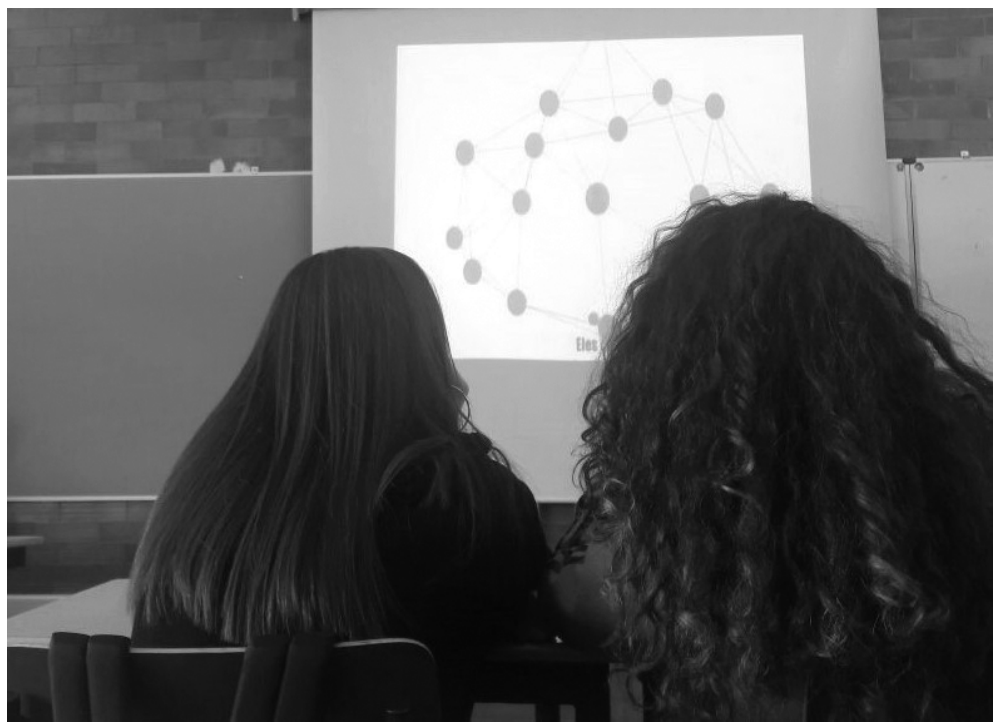

Fig. 4. The digital era and the city, indoor session.

Teenagers are frequent users of mobile devices - only one of the QI respondents didn't have a smartphone and $91 \%$ stated they were either 'constantly/connected all the time' or that they connected to the internet several times during the day, mainly for social purposes. Despite this frequent use, they weren't too keen on using their mobile phones during the sessions. As justification for this, they mentioned limited mobile data and the lack of memory storage capacity. It is expected that activities using ICT tools will be conducted in a subsequent phase of the thematic workshops with teenagers. However, in this first phase of intervention the process was "analogue" using "traditional" research tools and non-formal education principles.

Needs and ideas for public open spaces: A goal which had been set in the operationalization of some activities and which was not achieved was the direct identification of a single public open space in Alvalade which proved relevant to teenagers. The idea was to have them use this space as reference for the design of proposals and ideas for transformation in thematic workshop 4. However, during the sessions, the teenagers' struggle to identify a single public open space of reference in the neighbourhood became increasingly apparent. This can be explained since many live somewhere else and their spatial reference in Alvalade is only around the school or along the circulation paths between the school and the main transportation stops. Although the largest green area in the Alvalade neighbourhood - José Gomes Ferreira Park - is located very close to the school, and though it was mentioned often in the different materials, it became clear, from class interactions, that teenagers do not use this public space often. The public open space of reference 
for the thematic workshop 4 was then, due to these circumstances, chosen by the researchers based on structured observations. Marquês de Soveral Street, right in front of the school is a space used by students before and after classes and during breaks, and was therefore selected. Teenagers proposed, for this space, more parking, better accessibility, more greenery and equipment, such as benches, a kiosk or a playground. A reconfiguration of traffic was also suggested to broaden the available space and change the location of an intersection crossing. The final product was not the same in both classes - one produced a more structured descriptive memory (Fig. 5), the other a less structured set of ideas and identified needs. When addressing the suitability of a public open space to their needs, teenagers focused on the quality, diversity and availability of services and infrastructures, namely cafes, bathrooms, sports areas, water fountains, to name a few. And of extremely high importance to all of them was the existence of a good network of public transportation around the area. As mentioned above, many students live outside Alvalade or even Lisbon, which increases the importance of this service in their use of public space.

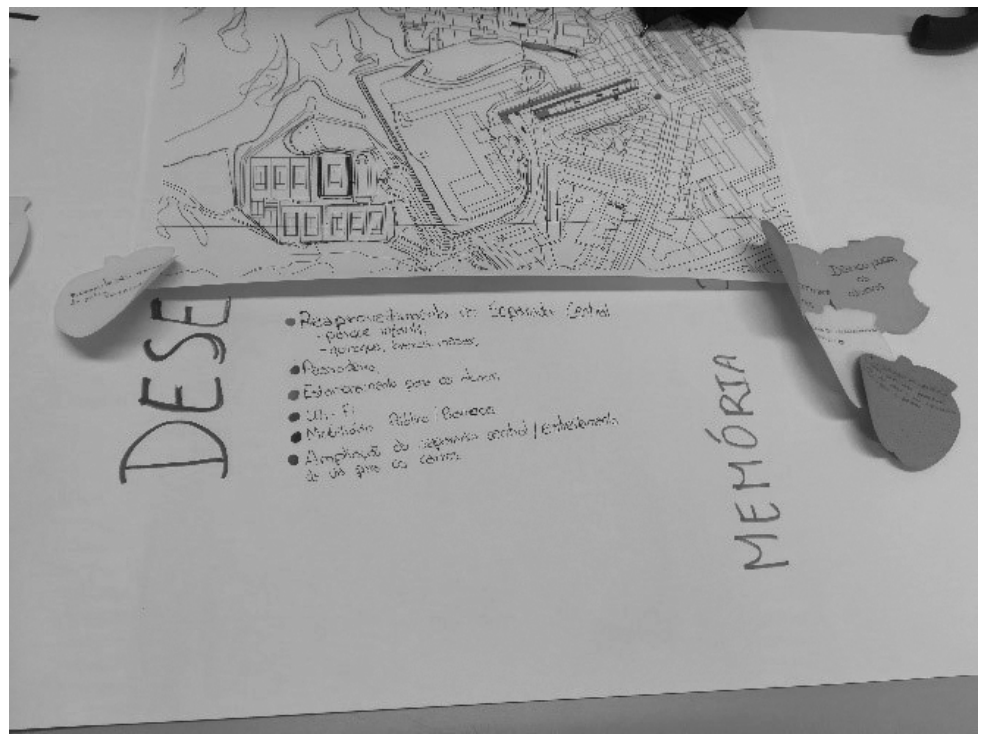

Fig. 5. Design of proposals for a teenager-sensitive public open space in the Alvalade neighbourhood.

\section{CONCLUSION}

This chapter aimed at reflecting on teenagers' participation and placemaking. A comparison was drawn between the initial expectations of researchers regarding a series of thematic workshops on urban planning that took place in the Alvalade neighbourhood (Lisbon) with the emerging topics of interest arising brought up by the teenagers involved. The reflections from the workshops' pilot phase allowed for a more informed development of the following sessions - which will take place in the same school, but with a different group of students. 
Teenagers are a group with particular needs, interests and aspirations, which are visible in all the scopes of their existence as individuals and as members of society. When considering instances of planning and design of public open spaces, teenagers' contribution is paramount for developing adequate places. When we consider teenagers in a broader sense, their needs and ideas hardly influence policies for many reasons. They are not often heard or invited to participate in the different processes of decision-making. Participative tools and processes frequently have age limitations which also exclude them. Moreover, teenagers themselves are not sensitive or motivated to participate, plus the tools to express their ideas are absent.

Furthermore, teenagers' education remains, in general, highly formal. Still, on a positive note, it has become increasingly more focused on matters of citizenship education, civic participation and articulation of the curricula with the local reality of students. However, citizenship education as understood in the curricula is neither clear nor effective. It gives precedence to civic education, of a purely formal nature, showing little initiative and student interaction with local communities. From this perspective, the "civic participation" of teenagers has been based on the acceptance of already defined social structures, to the detriment of critical thinking which truly truncated with the local context, thereby depriving them of an effective and enlightened public life. However, the experience of thematic workshops on urban planning discussed in this chapter revealed the potential of non-formal and interactive education - leaning via flexible activities and subjects complementary to the official curricula - by taking the "classroom" into different locations, such as the public open space. Experiences of engagement as this allow to raise teenagers' awareness to the space around them. Their formal educational setting can, then, be articulated with broader locations where social practices, norms and interactions take place at societal level. For teenagers, to ponder on the strategies to propose transformations of public spaces or on how to express their needs to professionals is not innocuous. It may constitute the spark that ignites their capacity to reflect on their broader role as members of society and on their rights and obligations as citizens.

\section{REFERENCES}

Almeida, I., Solipa Batista, J., Menezes, M. \& Smaniotto Costa, C. (2018). “Adolescentes e Cocriação Do Espaço Público. Oficinas Temáticas de Urbanismo 2017 - 2018. Relatório Preliminar Sobre o Estudo de Caso de Lisboa." Lisboa: Edições Universitárias Lusófonas. https://c3places.eu/ sites/default/files/ publications/Relatorio Oficinas Urbanismo 2407/8.pdf.

Armingeon, K. \& Schädel, L. (2015) Social Inequality in Political Participation: The Dark Sides of Individualisation. West European Politics, 38: I, I-27, DOI: 10.1080/0I402382.20 I4.92934I.

Banks, J. A. (2008). Diversity, group identity, and citizenship education in a global age. Educational researcher, 37(3), 129-139.

Borja, J. (2003). La Ciudad Conquistada. Madrid: Alianza Editorial.

Braun, V. \& Clarke, V. (2006) Using thematic analysis in psychology. Qualitative Research in Psychology, 3 (2), 77-I0I. 
Costa, J. P. (2002). Bairro de Alvalade: Um Paradigma no Urbanismo Português.Lisboa: Horizonte Arquitectura.

Giroux, H. (1980). The Politics of Student Resistance in Classroom Pedagogy. Journal of Education, vol 162, 3, pp.75-79.

Habermas, J. (1997). The Public Sphere. In R. Goodin; P. Pettit (orgs.), Contemporary Political Philosophy. (pp. 105-108). Oxford: Blackwell Publishers.

Holmes, B. (20I I). Citizens' engagement in policymaking and the design of public services. Department of Parliamentary Services. Canberra: Parliamentary Library, Research Paper I.

Laughlin, D. L., \& Johnson, L. C. (20I I). Defining and exploring public space: perspectives of young people from Regent Park, Toronto, Children's Geographies, 9 (November), 439-456. https://doi.org/https:// doi.org/ 10.1080/14733285.2011.590703.

Lourenço, F. (2019). Public spaces as gathering places of different location-in-movements: an intercultural approach. In M. Menezes \& C. Smaniotto (Edts). Neighbourhood \&City. Between digital and analogue perspectives, vol 3, 399-406.

Lefebvre, H. (1973). A Re-produção das relações de produção. Porto: Publicações Escorpião.

Passon, C., Levi, D., \& del Rio, V. (2008). Implications of adolescents' perceptions and values for planning and design. Journal of Planning Education and Research, 28(I), 73-85. https://doi.org/I0.1/77/ $0739456 \times 08319236$.

PPS (2018). Placemaking. What if we built our cities around places? Retrieved from: https://www.pps.org/ article/what-is-placemaking.

Schugurensky, D. \& Myers, J. (2003). Citizenship education: Theory, research and practice. Encounters on Education, Vol. 4, Fall 2003, pp. I-I0.

Smaniotto Costa, C., Almeida, I., Batista, J. \& Menezes, M. (2018). Envolver adolescentes no pensar a cidade: reflexão sobre oficinas temáticas de urbanismo no Bairro de Alvalade, Lisboa. Revista de Geografia e Ordenamento do Território (GOT), 15, I 17-142, http://dx.doi.org/10.17/27/got/2018.15.006

Stephens C. (2012). Urban inequities; urban rights: a conceptual analysis and review of impacts on children, and policies to address them. Journal of urban health : bulletin of the New York Academy of Medicine, 89(3), 464-85.

Valentine, G. (2004). Public Space and the Culture of Childhood. London: Ashgate Publishing. van Holm, E. J. (2019). Unequal Cities, Unequal Participation: The Effect of Income Inequality on Civic Engagement. American Review of Public Administration, 49(2) I35-I44. doi.org/I 0.1 I 77/02750740 I8 791217.

White, R (200I). Youth participation in designing public spaces [online]. Youth Studies Australia, 20(I), I8. PP. 18-26. Retrieved from: https://search.informit.com.au/documentSummary; dn=200 I09 |48;res= IELAPA ISSN: 1038-2569.

Wilhelmer, D. (2016). Society in need of transformation. Citizen-Foresight as a method to co-create urban future. Public Philosophy \& Democratic Education, 5(2), PP. 5I-72. DOI: 10.14746/ fped.2016.5.2.21. 